\title{
An evaluation of a free lunch initiative in a Northern Irish workplace
}

\author{
D. Schliemann, M. McKinley and J. Woodside \\ Centre for Public Health, Queen's University Belfast, Belfast, BT12 6BJ, Uk
}

The majority of UK adults are not meeting nutrition guidelines ${ }^{(1)}$ and, with obesity rates and associated disease risk factors becoming more prevalent, initiatives to address unhealthy lifestyle choices have become increasingly important. The workplace has been identified as a potentially effective environment for such interventions to promote diet and health in a large number of people ${ }^{(2,3)}$ which ultimately may benefit the company as a whole. Initiatives at work allow factors related to healthy eating, such as knowledge and skills, as well as external factors, such as the availability of healthy food and support from others to make healthy choices, to be addressed.

The Ulster Carpets controlled pilot study addresses solely environmental factors and aims to evaluate the introduction of free, healthy lunches in the workplace (Site A) compared with a control site who did not receive the free lunches (Site B) on employees' overall health, diet and job satisfaction. Quantitative baseline data was collected in the form of two $24 \mathrm{~h}$ diet recalls ${ }^{(4)}$, a health and lifestyle questionnaire and a health assessment measuring body mass index (BMI), waist circumference (WC) and blood pressure (BP). Semi-structured interviews were conducted with stakeholders and employees as part of qualitative data collection to allow identifying barriers to and drivers of dietary change. Data collection was carried out at baseline in September 2014 and will be repeated 6 months after the introduction of the lunches.

Preliminary baseline results reflect similar issues as currently seen throughout the UK, i.e. the mean BMI of employee's falls into the overweight category and employees have a diet high in saturated fat, non-milk extrinsic sugars and consume less than five portions of fruits and vegetables per day (see table).

\begin{tabular}{|c|c|c|c|c|c|}
\hline & \multicolumn{2}{|c|}{ Site A (intervention) } & \multicolumn{2}{|l|}{ Site B (control) } & \multirow[b]{2}{*}{ Recommended values } \\
\hline & Males (n 10) & Females $(n 9)$ & Males $(n$ 11) & Females $\left(\begin{array}{ll}n & 11)\end{array}\right.$ & \\
\hline Age (years) & $50 \cdot 4(4 \cdot 8)$ & $43 \cdot 4(11 \cdot 1)$ & $42 \cdot 2(10 \cdot 2)$ & $44 \cdot 6(7 \cdot 4)$ & $\mathrm{n} / \mathrm{a}$ \\
\hline BMI $\left(\mathrm{kg} / \mathrm{m}^{2}\right)$ & $30 \cdot 8(7 \cdot 0)$ & $27.8(7.7)$ & $26 \cdot 5(2 \cdot 6)$ & $25 \cdot 8(4 \cdot 1)$ & $18 \cdot 5-24 \cdot 9$ \\
\hline WC (cm) & $99.0(17 \cdot 7)$ & $86 \cdot 8(20 \cdot 3)$ & $92 \cdot 6(9 \cdot 6)$ & $86 \cdot 2(12 \cdot 4)$ & $\mathrm{n} / \mathrm{a}$ \\
\hline $\mathrm{SPB}(\mathrm{mmHg})$ & $129 \cdot 6(11 \cdot 35)$ & $121.6(11.9)$ & $137 \cdot 2(12 \cdot 1)$ & $123 \cdot 5(15 \cdot 1)$ & 120 \\
\hline DBP (mmHg) & $78 \cdot 1(10 \cdot 17)$ & $76 \cdot 2(10 \cdot 2)$ & $83.4(10 \cdot 9)$ & $73 \cdot 8(10 \cdot 5)$ & 80 \\
\hline Energy (kcal) & $2002.0(742.9)$ & $1781 \cdot 1(708 \cdot 2)$ & $2217 \cdot 2(1002 \cdot 7)$ & $1537.4(455 \cdot 2)$ & M:2500 F: 2000 \\
\hline SFA intake $(\%)$ & $15 \cdot 4(3 \cdot 5)$ & $14 \cdot 1(4 \cdot 4)$ & $12 \cdot 5(4 \cdot 3)$ & $11 \cdot 0(5 \cdot 0)$ & $\leq 11 \%$ \\
\hline NMES $(\%)$ & $18 \cdot 4(4 \cdot 8)$ & $20 \cdot 6(9 \cdot 7)$ & $18 \cdot 9(10 \cdot 3)$ & $23 \cdot 8(9 \cdot 6)$ & $\leq 11 \%$ \\
\hline FV (portions/day) & $2 \cdot 3(1 \cdot 0)$ & $2 \cdot 2(0 \cdot 8)$ & $2 \cdot 6(0 \cdot 9)$ & $2 \cdot 3(0 \cdot 8)$ & $\geq 5$ \\
\hline
\end{tabular}

All values reported as means (SD).

Thematic analysis of the interviews revealed that availability, time and convenience were the main factors that affect workers' lunch choices. In terms of the free lunch provision, it was important to employees that lunches would be seasonal (i.e. warm dishes in the winter), an appropriate meal size would be provided for lunch and that a variety of food would be offered. The workplace potentially offers a setting in which to change diet behaviours by changing the eating environment and making healthy diet choices easier to access.

1. Bates B, Lenox A, Swan G et al. (2010) Public Health England, London.

2. Geaney F, Kelly C, Greiner BA, et al. (2013) Prev Med, 57, 438-47.

3. Ni Mhurchu C, Aston LM \& Jebb SA (2010) BMC Publ Health 10, 62-69.

4. Nelson M, Erens B, Bates B, et al. (2007). FSA. HMSO: London. 